\title{
Shock tube study on auto-ignition characteristics of kerosene/air mixtures
}

\author{
ZHANG YingJia ${ }^{1}$, HUANG ZuoHua $^{*}$, WANG JinHua ${ }^{1} \&$ XU ShengLi ${ }^{2}$ \\ ${ }^{1}$ State Key Laboratory of Multiphase Flow in Power Engineering, Xi' an Jiaotong University, Xi' an 710049, China; \\ ${ }^{2}$ Department of Modern Mechanics, University of Science and Technology of China, Hefei 230026, China
}

Received August 6, 2010; accepted November 22, 2010

\begin{abstract}
Ignition delay times are obtained for kerosene/air mixtures behind the reflected shock waves at temperatures between 1445 and $1650 \mathrm{~K}$, at a pressure of $0.11 \mathrm{MPa}$ and an equivalence ratio of 1.0. A nebulization device with Laval nozzle is used to nebulize kerosene and form an aerosol phase, which evaporates and diffuses rapidly behind the incident shock waves. Mixtures auto-ignite behind the reflected shock waves. An ICCD is used to visualize the kerosene/air mixture's ignition characteristics. The mixture's ignition intensity increases with increase in initial temperature. Continuous and irregular flames exist below $1515 \mathrm{~K}$ while plane and discontinuous flames exist over $1560 \mathrm{~K}$. Ignition delay times decrease with increase in initial temperature. Experimental data shows good agreement with results reported previously in the literature. A new surrogate (consisting of 10\% toluene, 10\% ethylbenzene and $80 \% \mathrm{n}$-decane) is proposed for kerosene. Honnet et al.'s mechanism is used to simulate the ignition of kerosene with calculations agreeing well with the experimental data. The sensitivity of reaction $\mathrm{H}+\mathrm{O}_{2}<=>\mathrm{OH}+\mathrm{O}$, which shows the highest sensitivity to the ignition delay time, increases with an increase in temperature. The chain breaching reaction of $\mathrm{CH}_{3}$ with $\mathrm{O}_{2}$ accelerates the total reaction rate and the $\mathrm{H}$-atom abstraction of $\mathrm{n}$-decane controls the total reaction rate. The rate of production and instantaneous heat production indicate that two reactions, $\mathrm{H}+\mathrm{O}_{2}<=>\mathrm{OH}+\mathrm{O}$ and $\mathrm{O}+\mathrm{H}_{2}<=>\mathrm{OH}+\mathrm{H}$, are the key reactions to the formation of $\mathrm{OH}$ radicals, as well as the main endothermic reaction. However, the reaction of $\mathrm{R} 3$ is the main heat release reaction during ignition. Flame structure analysis shows that initial pressure is increased slightly as $\mathrm{CO}$ and $\mathrm{H}_{2} \mathrm{O}$ will appear before main ignition.
\end{abstract}

shock tube, ignition delay time, kerosene, sensitivity

Citation: Zhang Y J, Huang Z H, Wang J H, et al. Shock tube study on auto-ignition characteristics of kerosene/air mixtures. Chinese Sci Bull, 2011, 56: 1399-1406, doi: 10.1007/s11434-010-4293-y

Kerosene, a common hydrocarbon, is used as a fuel in aerospace applications, as a solvent, and for lighting. In the aerospace field, kerosene is a preferred fuel for scramjets and pulsed detonation engines (PDE) because of its stable thermodynamic properties and high calorific value.

Investigation of the ignition delay time of kerosene is important for improving its combustion efficiency, increasing heat efficiency and reducing pollutants. Fuel residence times in the scramjet and PDE are very short, and of the same order of magnitude as ignition delay times. Therefore, ignition delay times strongly influence heat generation rates. The ability to control the kerosene's ignition delay time is

*Corresponding author (email: zhhuang@mail.xjtu.edu.cn) crucial in combustor design and to ensure efficient combustion [1]. Kerosene composition is complex, making it difficult to investigate its ignition delay time. In recent years therefore, many researchers have focused on simulating the behavior of kerosene by using surrogates. Kerosene combustion mechanisms contain hundreds of species and thousands of elementary reactions, requiring extended computational times when using CFD software. A reduced number of reactions in mechanisms is required to decrease the computational time with satisfactory accuracy. The ignition delay time is an important parameter for building and validating mechanisms. Furthermore, ignition delay times of kerosene will provide basic information for exploring kerosene surrogates and increasing the understanding of kero- 
sene combustion characteristics.

Many experimental devices can be used to investigate ignition delay time, such as flow reactor, rapid compression machine, shock tube and homogenous charge compression ignition engines. The shock tube is an ideal device for this purpose as it can be used to increase and control temperature and pressure to a high level within several milli- or microseconds. It is also able to determine the initial ignition point and ignition delay time. Recently, shock tube studies on the combustion characteristics of kerosene focused mainly on the use of surrogates. Char et al. [2] investigated ignition delay times of JP-8 droplets behind reflected shock waves and analyzed the effect of oxygen concentration, incident shock velocity, size and droplet distribution and initial temperature. Vasu et al. [3] used a heated high pressure shock tube to investigate ignition delay times of jet fuels behind reflected shock waves at $874-1220 \mathrm{~K}$ and $1.7-5.1 \mathrm{MPa}$, and a simple 1/P dependence was found for ignition delay times. They also discussed the effect of variation of equivalence ratio and Negative Temperature Coefficient (NTC) behavior. Ranzi et al. [4] investigated the chemical kinetic process of heavy hydrocarbons using stirred and flow reactors for premixed and diffusion flames, and fuel droplet combustion under microgravity conditions, and developed detailed mechanisms for heavy hydrocarbons. Honnet et al. [5] studied the critical condition for extinction, auto-ignition, and the volume fraction of soot on a mixture of $80 \%$ n-decane and $20 \%$ 1,2,4-trimethylbenzene using a counter-flow configuration, and developed a simplified mechanism for kerosene. It is difficult to build kinetic models of practical fuels like kerosene and jet fuels mainly because of the lack of reliable experimental data of ignition delay times.

In this study, a shock tube with Laval nozzle nebulization system is used to study the ignition of kerosene/air mixtures at $1405-1650 \mathrm{~K}, 0.11 \mathrm{MPa}$ and an equivalence ratio of 1.0. Visualization can indicate auto-ignition characteristics of kerosene/air mixtures at high temperatures to obtain ignition delay times. The study can provide reliable data for the development of kinetic reaction mechanisms for kerosene. A new three-component surrogate ( $10 \%$ toluene, $10 \%$ ethylbenzene and $80 \%$ n-decane) is used to simulate kerosene using Honnet et al.'s [5] mechanism to determine whether ignition delay times agree with experimental results. A sensitivity analysis is used to indicate which are the key reactions influencing kerosene ignition. Furthermore, the rate of production (ROP) and instantaneous heat production of $\mathrm{OH}$ radicals is used to identify important heat generation reactions in the ignition of the three-component surrogate.

\section{Experimental setup and procedures}

\subsection{Experimental setup}

Figure 1 shows the experimental setup. The main body consists of a stainless steel tube with $130 \mathrm{~mm} \times 80 \mathrm{~mm}$ cross section. A $25 \mu \mathrm{m}$ PVC film separates the shock tube into the driver and driven sections. Pure helium is used as the high pressure driving gas. A mechanical prod is applied to break the diaphragm.

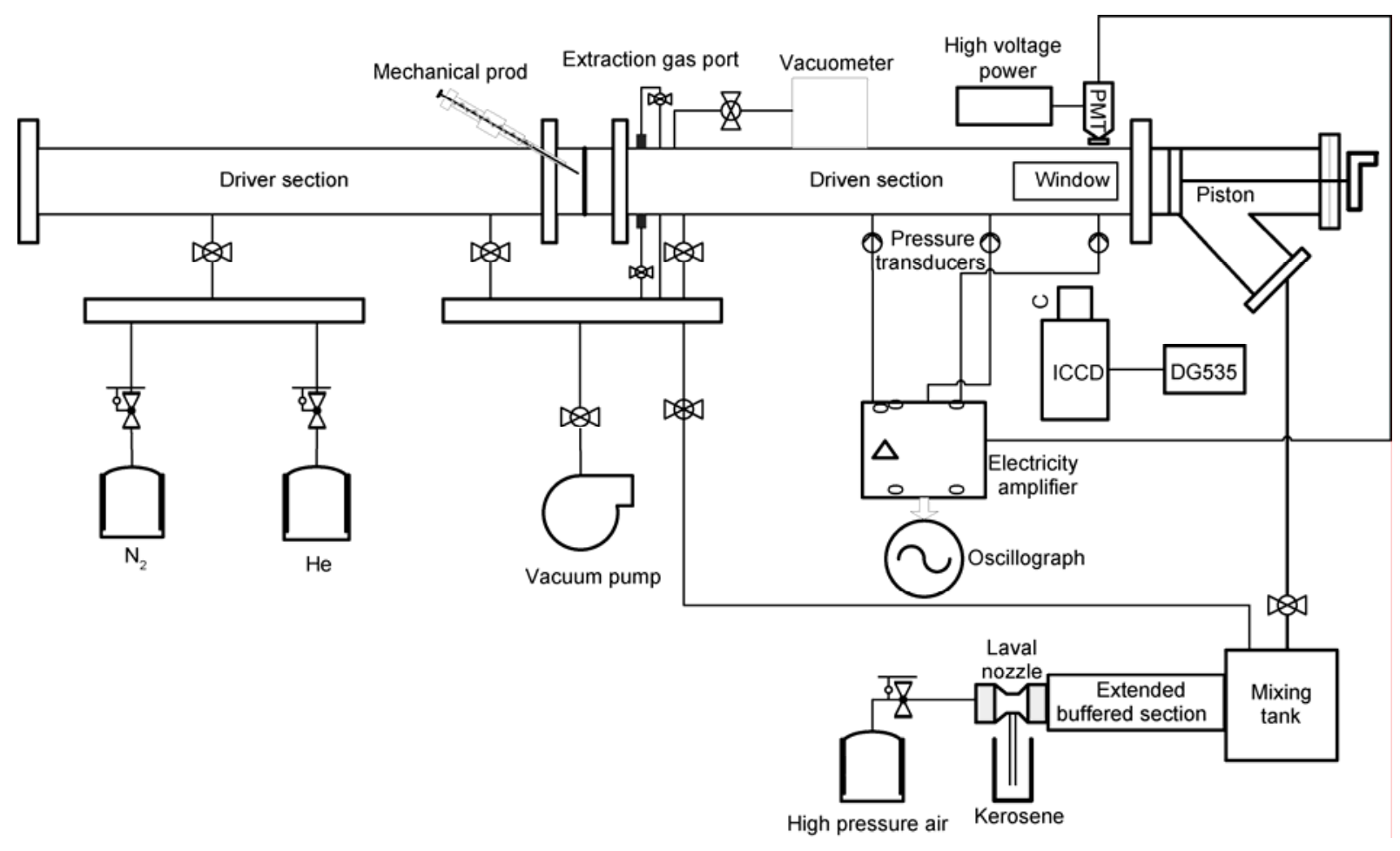

Figure 1 Schematic of shock tube experiment. 
The incident shock speed is measured using two fast response pressure transducers (PCB Model 113B26) and the velocity of the incident shock at the end wall is determined through linear extrapolation. Typical shock attenuation, which is defined as the normalized slope of axial velocity extrapolated to the end wall (in $\% / \mathrm{m}$ ), is less than $3 \%$. The kerosene/air mixture ignition pressure is monitored using a piezoelectric pressure transducer with acceleration compensation (PCB Model 113B03) located $20 \mathrm{~mm}$ from the end wall. The $\mathrm{OH}^{*}$ emission is detected using a lens/slit setup (using a filter with half-band width of $5 \mathrm{~nm}$ and wavelength of $307 \mathrm{~nm}$ ) and photomultiplier (Hamamatsu CR115) with high intensity luminescence located at an observation window in the side wall and in the same axial direction. The mixture ignition process is recorded using the Intensified Charged Coupled Camera (ICCD) (PI MAX $1 \mathrm{KUV})$ which is controlled by a Digital Delay Pulse Generator (Stanford DG535) based on the $\mathrm{OH}^{*}$ emission signal. Before the test, ultimate pressures in the driven and driver sections and stainless steel mixing tank are reduced to a vacuum of less than $1.33 \times 10^{-1} \mathrm{~Pa}$ using a Roots pump (ZJP-70) and the leak outgassing rate was maintained at a level lower than $5 \times 10^{-1} \mathrm{~Pa} / \mathrm{min}$. A Laval nozzle was used to nebulize the kerosene and mix it with air in the mixing tank.

In this study, the ignition delay time is defined as the time interval between the arrival of the reflected shock wave and the onset of ignition at the side wall observation window (Figure 2). The diagnosing signals are consistent with both the second onset of pressure and maximum $\mathrm{OH}^{*}$ emission, respectively. The $\mathrm{CH} 1, \mathrm{CH} 2, \mathrm{CH} 3$ signals located $664.5 \mathrm{~mm}, 237 \mathrm{~mm}$ and $20 \mathrm{~mm}$ from the end wall of the shock tube are consistent with three pressures, and the $\mathrm{CH} 4$ signal corresponds to the $\mathrm{OH}^{*}$ emission. When the diaphragm is broken, a plane shock wave is formed and propagates toward the driven section along the axis of the tube. A rarefaction wave is formed and propagates towards the driver section. The first striking step of the pressure appears when the incident shock wave passes the transducers at the end wall, and the pressure and temperature of the mixtures increase. The second pressure rise appears when the reflected shock wave passes the transducers at the end wall, and the pressure and temperature of the mixtures increase again, as shown by $\mathrm{CH} 3$ in Figure 2. Reflected shock conditions are determined from the standard onedimensional shock relations and because the experimental time is of millisecond magnitude or even shorter, the whole process is kept approximately adiabatic within this short time. Uncertainty in the initial reflected shock temperature is estimated to be $\pm 15 \mathrm{~K}$.

\subsection{Nebulization and mixing of kerosene}

RP-3 kerosene, which includes 92\% saturated hydrocarbons, unsaturated hydrocarbons and $7.5 \%$ aromatic compounds, was used in this study. A nebulization device,

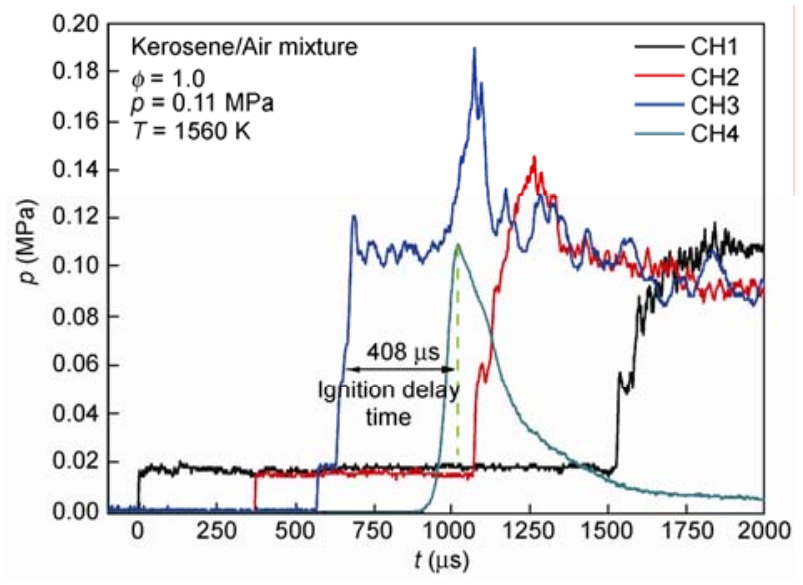

Figure 2 Ignition delay time of kerosene/air mixtures. Reflected shock conditions: $p=0.11 \mathrm{MPa}, T=1475 \mathrm{~K}, \phi=1.0$, ignition delay time $=408 \mu \mathrm{s}$.

composed of three parts, the Laval nozzle, extended buffered section and mixing tank, produces hypersonic flow for sufficient kerosene nebulization and uniform mixing with air, as shown in Figure 1. As the nozzle throat pressure is 0.528 times the inlet pressure, the air flow velocity and nozzle throat pressure are controlled by the exit pressure of the high pressure air. The kerosene/air mixing ratio was calculated according to the required stoichiometric ratio. These reagents were introduced into the mixing tank at the same time or with a slight delay for air to ensure full kerosene atomization. If the pressure difference is too large, the velocity of the kerosene inhaled into the measuring cylinder will be too high, and the momentum and kinetic energy between the hypersonic flow and kerosene will not be exchanged adequately. This may induce a non-uniform distribution of droplets, which will not form a steady aerosol and restrict further nebulization in the shock tube. If the pressure difference is too small, the velocity of the kerosene inhaled into the measuring cylinder will be too low, air will predominate in the mixing tank making it difficult to control the equivalence ratio. In this study, an inlet and nozzle throat pressure of 0.17 and $0.09 \mathrm{MPa}$ are selected to ensure that kerosene and air enter the mixing tank at the same time. The exchange of momentum and kinetic energy between hypersonic flow and kerosene is sufficient, the kerosene droplets are broken into smaller particles and an aerosol phase is maintained in the mixing tank. An extended buffered section is located between the Laval nozzle and the mixing tank to avoid wall adsorption effects in the mixing tank.

Two bleeder valves are located near the diaphragm to ensure the uniform distribution of mixtures along the entire driver section of shock tube, and to provide favorable conditions for further nebulization. Kerosene droplets are broken into smaller particles to obtain rapid evaporation and diffusion. Kerosene becomes the vapor phase when the incident shock wave passes the kerosene aerosol. Mixture ignition occurs as pressure and temperature increase when 
the reflected shock wave arrives at the measurement position. Liao and $\mathrm{Xu}$ [6] applied a tridimensional lasergranularity instrument based on Mie dispersion theory and Planar Laser Induced Fluorescence (PLIF) to visualize the aerosol mixtures. Results indicate that the average particulate size of the aerosol is between 2 and $5 \mu \mathrm{m}$ and a steady and suspensible aerosol phase can be formed according to aerosol theory. In this study, the uncertainty of the equivalence ratio is less than $2 \%$. Furthermore, Davidson et al. [7] reported that the nebulization particle sizes were independent of fuel type.

\section{Results and discussion}

\subsection{Effect of temperature on the auto-ignition process of kerosene/air mixtures}

Figure 3 shows the auto-ignition of kerosene/air mixtures under the same trigger delay using DG535 and at five temperatures: 1445, 1515, 1560, 1575 and $1650 \mathrm{~K}$ (Figures 3(a)-(e)). The arrow shows the direction of reflected shock wave propagation. The mixture ignition luminous intensity increases with increase in temperature and becomes weaker with a continuous and irregular flame at temperatures below $1515 \mathrm{~K}$. This is because of the relatively low incident shock wave speed; mixtures have sufficient time to evaporate and diffuse and then form uniformly before the reflected shock wave reaches them. At this point, some chemical reactions have already taken place and isolated flame kernels are formed as the mixture temperature and pressure increase. Subsequently, the isolated flame kernels intertwine and spread gradually to form a continuous, uniform and irregular flame shape. A clear flame front is not observed as the flame develops slowly and the flame speed is lower than the reflected shock front speed. Wang et al. [8] also observed similar phenomena in their study. The reflected shock wave moves from the observation window toward the driver section which leads to an increase in ignition delay time of the kerosene/air mixtures at low temperature. The ignition luminous intensity of the mixtures becomes stronger and a regular and discontinuous flame is presented at temperatures over $1560 \mathrm{~K}$. This is because of the relatively high incident shock wave speed; mixtures have insufficient time to evaporate and diffuse before the reflected shock wave reaches them. This indicates that the flame luminous intensity is high where good mixing occurs and weak where poor mixing occurs. Kernels developed in the plane flame when they were ignited simultaneously at the same position instead of as isolated flame kernels. The supersonic flame front propagates toward the driver section and catches up to the reflected shock wave.

Furthermore, Figure 3 reveals a very interesting feature. Strong or weak ignitions are not observed at a certain distance from the end wall of the shock tube. This is because part of the mixture is firstly consumed before significant ignition occurs. The distance from the end wall of the shock tube influences the evaporation, diffusion and subsequent nebulization and mixing. Therefore, the ignition delay time of the mixtures increases. While the shock intensity decreases because the effect of the boundary layer is at a longer distance from the end wall of the shock tube, the pressure and temperature of this portion of the mixtures is lower than the thermodynamic state of the mixtures. This also leads to an increase of ignition delay times for this mixture.

\subsection{Ignition delay times of kerosene/air mixtures}

The thermodynamic state behind the reflected shock wave is calculated using standard one-dimensional shock relations. Relaxation phenomena exist in the oxygen and nitrogen system in the real shock tube and therefore, the reflected shock conditions between the ideal and real flow deviate. However, the duration between when the incident and reflected shock waves interact with the experimental mixture is short and the relaxation speed of the gases is lower than the shock wave speed. Oxygen and nitrogen can reach the equilibrium state in the microsecond time scale. Therefore, the relaxation effects can be ignored. Table 1 shows a comparison between the calculated and measured values for the pressures behind the reflected shock wave. The uncertainty is less than $3.7 \%$, thus this assumption is acceptable in this analysis.

Figure 4 shows the effects of temperature on ignition delay times of the kerosene/air mixtures compared with the ignition delay times of $\mathrm{n}$-decane and toluene as reported by Horning et al. [9] and Vasudevan et al. [10]. Initial reflected shock conditions are at temperatures of 1445 to $1650 \mathrm{~K}$, an equivalence ratio of 1.0 , and a pressure of $0.11 \mathrm{MPa}$. Results indicate that a linear relationship exists between the reciprocal of temperature and the logarithm of the ignition delay times, corresponding to the Arrhenius-type expressions.

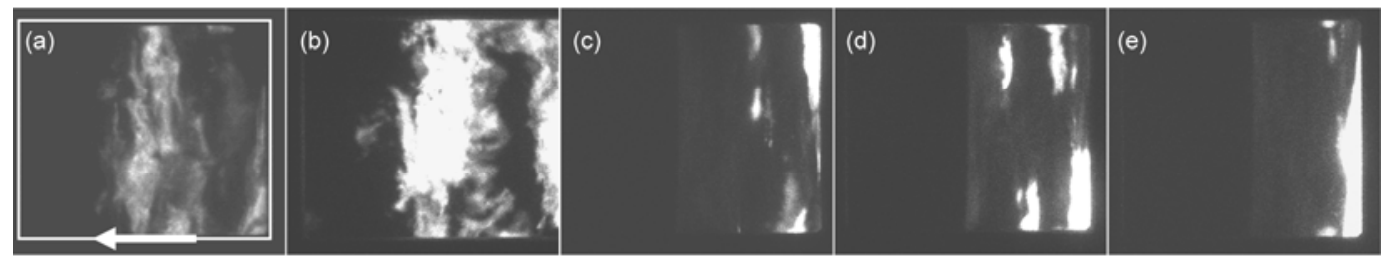

Figure 3 Ignition process of the kerosene/air mixtures under same trigger delay at different temperatures. 


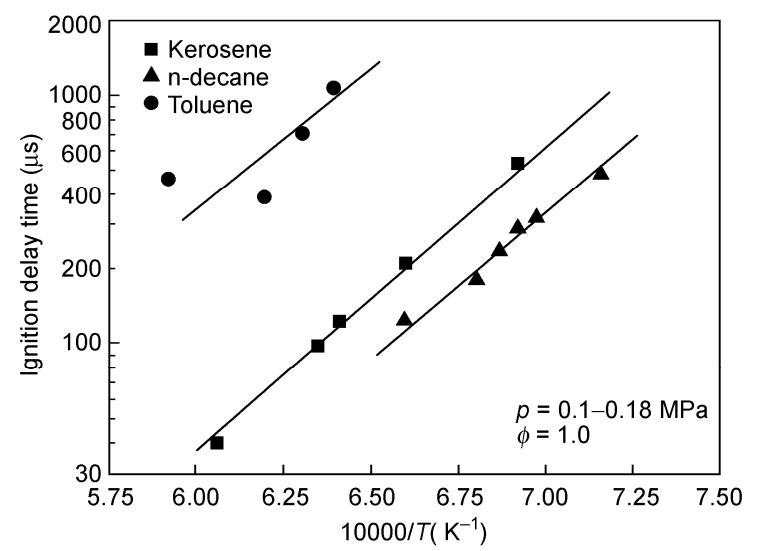

Figure 4 Comparison of ignition delay times in kerosene, n-decane [7] and toluene [8]. $T=1445-1650 \mathrm{~K}, p=0.1-0.18 \mathrm{MPa}, \phi=1.0$.

Table 1 Comparison between the calculated and measured pressure values

\begin{tabular}{ccc}
\hline $\begin{array}{c}\text { Calculated } \\
(\mathrm{MPa})\end{array}$ & $\begin{array}{c}\text { Measured } \\
(\mathrm{MPa})\end{array}$ & $\begin{array}{c}\text { Uncertainty } \\
(\%)\end{array}$ \\
\hline 0.111 & 0.109 & -1.8 \\
0.110 & 0.107 & -2.8 \\
0.107 & 0.106 & -0.9 \\
0.104 & 0.108 & 3.7 \\
\hline
\end{tabular}

The global activation energy is almost constant between 1445 and $1650 \mathrm{~K}$. Attenuation of the incident shock wave, the boundary layer effects and interaction between the reflected shock wave and boundary layer can be ignored because of the higher experimental temperatures, stronger shock intensity and shorter laboratory times. The reflected shock pressure is increased slightly before significant ignition as some pyrolytic decomposition reactions occur slowly before the primary ignition and heat is generated. This will lead to measured values being slightly lower than the real values of the ignition delay times, a phenomenon known as pre-ignition.

The results show that the ignition delay times of n-decane are the longest while those of toluene are the shortest under the same conditions. Also, the ignition delay times of kerosene approximate those of n-decane. The slopes of the three fuels are identical, which indicates that the activation energy of the three fuels is the same. $\mathrm{N}$-decane and aromatics are the key components for kerosene. Kerosene ignition can therefore be simulated using n-decane and aromatic mixtures, which in turn can provide experimental data for simplifying the kinetics model of kerosene.

\section{Chemical kinetic analysis}

Kerosene is composed of alkane, aromatic and unsaturated hydrocarbons with the n-decane and aromatic composition being the highest. A detailed kinetic mechanism of kerosene combustion using a surrogate is reported by Dagaut and Cathonnet [11]. Patterson et al. [12] reported on the devel- opment of such a mechanism for modeling of kerosene. Edwards and Maurice [13] investigated surrogate mixtures having 1 to 10 hydrocarbons, similar to aviation fuel, and obtained a desirable tractability and reproducibility in designing jet injectors and propelled combustors.

\subsection{Calculated procedure}

The shock tube can provide an almost ideal homogeneous, adiabatic environment prior to the ignition of mixtures. Reflected shock conditions can be simulated using CHEMKINII with Senkin code where constant volume and adiabatic boundary conditions are assumed. The Differential Algebraic Sensitivity Analysis Code (DASAC) program based on BDF format is applied to perform time-integral and one-step sensitivity analysis. The non-linear differential equation, which describes the temperature and mass fraction of species, and the linear differential equation, which describes the one-step sensitivity to temperature and the species reaction rate, are solved. The definition of ignition delay time is consistent with the experiment because it allows comparability with the experiments. The temperature calculation step is $10 \mathrm{~K}$.

Honnet et al.'s [5] mechanism includes 120 species and 900 reactions bases on detailed n-decane and 1,2,4-trimethylbenzene mechanisms. The rate coefficient of the elementary reaction,

$$
\mathrm{HO}_{2}+\mathrm{HO}_{2}<=>\mathrm{H}_{2} \mathrm{O}_{2}+\mathrm{O}_{2}
$$

was improved. Ignition delay times of main components of kerosene such as n-decane, toluene and ethylbenzene are calculated using Honnet et al.'s [5] mechanism. Calculated results are compared with those from experiments, as shown in Figure 5. The calculated activation energy shows a slight discrepancy and the results show a slight difference to the experiment (see Figure 4). A comparison between the calculated and experimental data indicates that the kerosene activation energy approximates that of ethylbenzene, which is different from the activation energy of n-decane and kerosene predicted by Dagaut and Cathonnet [11]. The study shows that the ignition delay time of kerosene is between that of aromatics and alkanes. This is consistent with the results reported by Patterson et al. [12]. Here, a surrogate is simulated by the combination of toluene, ethylbenzene and n-decane. The ignition delay times of the ternary surrogate viz. $10 \%$ toluene, $10 \%$ ethylbenzene and $80 \%$ n-decane mixtures are calculated using Honnet et al.'s [5] mechanism and the results show good agreement with the experimental results of kerosene.

\subsection{Sensitivity analysis and rate of production of $\mathrm{OH}$ radical}

To reduce the commercial software calculation time required e.g. for CFD, a simplified kinetic mechanism is necessary. 


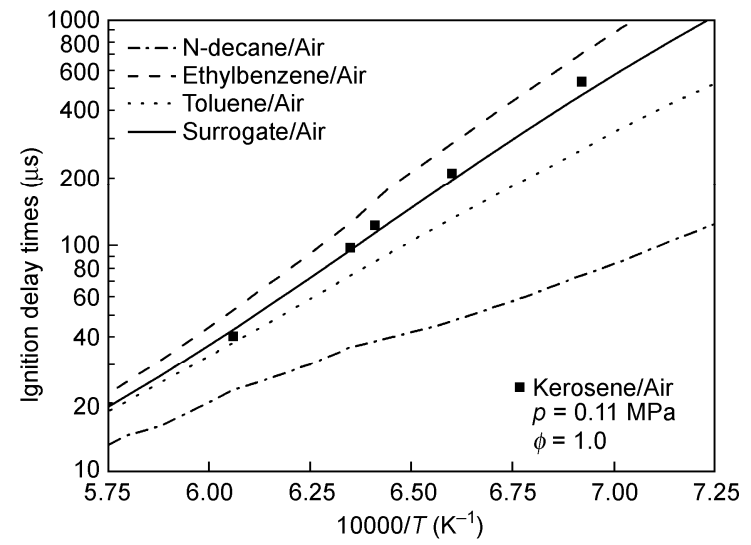

Figure 5 Comparison of ignition delay times between calculations and current experiment using Honnet et al.'s [5] mechanism. $p=0.11 \mathrm{MPa}$, $\phi=1.0$.

Sensitivity analysis and ROP are usually used to simplify the mechanism $[14,15]$. The coefficients forming the normalized sensitivity matrix can be obtained from,

$$
S_{i}\left(F, k_{i}\right)=\left\{\mathrm{d} F(t) / \mathrm{d} k_{i}\right\}\left\{k_{i} / F(t)\right\},
$$

in which $F(t)$ is the control equation of the individual reaction parameter and $k_{i}$ is the rate of the $i$ th reaction. In this study, the ignition delay time, equation $\tau(t)$, is selected as the control equation.

The kinetic reaction mechanism is based on a general scheme that includes initiation from thermal decomposition and reaction with $\mathrm{O}_{2}$, propagation via $\mathrm{H}$-atom abstraction by small radicals, radical decomposition, isomerization and reaction with $\mathrm{O}_{2}$ [16]. In this study, a mixture of $10 \%$ toluene, $10 \%$ ethylbenzene and $80 \%$ n-decane is used to simulate kerosene.

Figure 6 shows the sensitivity analysis of the ignition delay time of the main elementary reactions for the surrogate at $1445 \mathrm{~K}, 1515 \mathrm{~K}$ and $1560 \mathrm{~K}, 0.11 \mathrm{MPa}$ and an equivalence ratio of 1.0. The analysis reveals seven main elementary reactions for the surrogate, R1, R34, R69, R71, R138, R141 and R329, and thirteen main species, $\mathrm{O}, \mathrm{H}, \mathrm{OH}$, $\mathrm{HO}_{2}, \mathrm{HCO}, \mathrm{H}_{2}, \mathrm{CO}, \mathrm{CH}_{3}, \mathrm{CH}_{2} \mathrm{O}, \mathrm{CH}_{3} \mathrm{O}, \mathrm{C}_{2} \mathrm{H}_{3}, \mathrm{C}_{2} \mathrm{H}_{4}$ and $\mathrm{C}_{2} \mathrm{H}_{5}$ using Honnet et al.'s [5] mechanism. The major chemical reactions in the ignition process are dependent on $\mathrm{H}$ and $\mathrm{OH}$ formation and consumption. The oxidation reaction is suppressed by R329 and R34 and the reaction rate is decreased to lengthen ignition delay times. The oxidation reaction is controlled by $\mathrm{R} 1, \mathrm{R} 69, \mathrm{R} 71, \mathrm{R} 138$ and $\mathrm{R} 141$ and the reaction rate is increased to shorten ignition delay times. The sensitivity coefficient of R1 increases and those of R34 and R239 decrease with increase in temperature. R1 plays a dominant role during the ignition process, leading to the decrease of ignition delay time. This is consistent with the analysis above. Meanwhile, the chemistry reactions of some small radicals are also important, such as the consumption reaction of $\mathrm{CH}_{3}$ with $\mathrm{HO}_{2}$ in $\mathrm{R} 69$ and oxidation reactions of

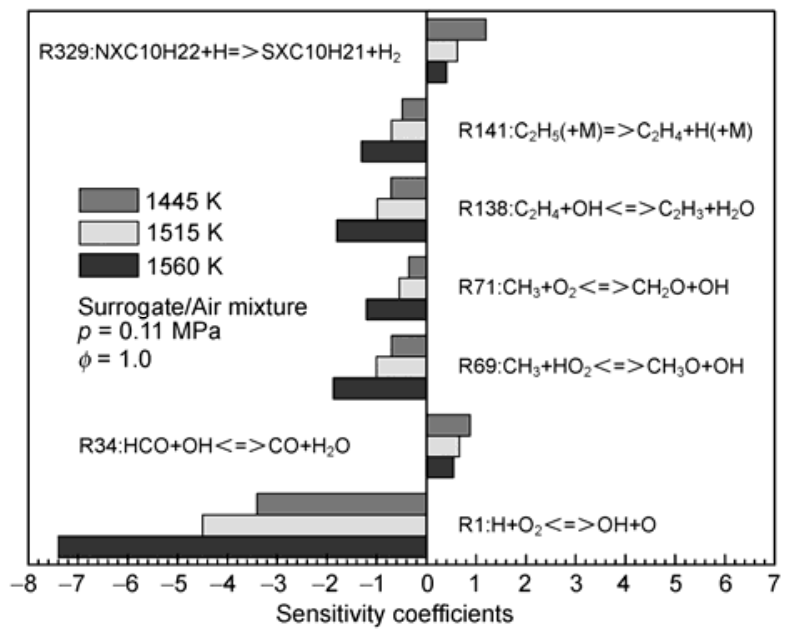

Figure 6 Sensitivity analysis of surrogate at different temperatures using Honnet et al.'s [5] mechanism.

$\mathrm{CH}_{3}$ with $\mathrm{O}_{2}$ in $\mathrm{R} 71$. The decomposition of n-decane as attacked by $\mathrm{H}$-atom abstraction contributes to an increase in ignition delay time at low temperature. Shen et al. [17] pointed out that the production and consumption of $\mathrm{HO}_{2}$ plays an important role in the chain reactions of heavy hydrocarbon fuels. Measurement of $\mathrm{HO}_{2}$ concentration becomes key to reducing and optimizing heavy fuel mechanisms.

The $\mathrm{R} 1$ reaction plays the most important role in the combustion of hydrocarbons and the concentration of $\mathrm{OH}$ can reflect the ignition delay time and auto-ignition characteristic. Figure 7 shows the ROP analysis for the $\mathrm{OH}$ radical and instantaneous heat production during ignition of the surrogate at $1445 \mathrm{~K}, 0.11 \mathrm{MPa}$ and an equivalent ratio of 1.0 using Honnet et al.'s [5] mechanism. OH radical concentration is determined by reactions $\mathrm{R} 1, \mathrm{R} 2, \mathrm{R} 3, \mathrm{R} 4, \mathrm{R} 20$ and R34. The peak value of the total rate of production of $\mathrm{OH}$ corresponds to the ignition starting point. The formation of an $\mathrm{OH}$ radical is controlled by $\mathrm{R} 1$ and $\mathrm{R} 2$, and consumption of the $\mathrm{OH}$ radical is dominated by $\mathrm{R} 3$ and $\mathrm{R} 20$. Heat generation shows that chain branching $\mathrm{R} 1$ is the main endothermic reaction, while $\mathrm{R} 3$ is the main heat generation reaction because of water production during ignition of the surrogate. Curran et al. [18] pointed out that the reactions of $\beta$ chemical bonds of the alkyl radical significantly influence the ignition delay time.

\subsection{Analysis of flame structure}

Figure 8 shows the flame structure of the surrogate during ignition at $1445 \mathrm{~K}, 0.11 \mathrm{MPa}$ and an equivalent ratio of 1.0 and gives the temperature distribution and concentrations of the main species $\mathrm{O}_{2}, \mathrm{H}_{2} \mathrm{O}, \mathrm{CO}_{2}, \mathrm{OH}, \mathrm{CO}$ and $\mathrm{H}$ as a function of reaction time. Oxygen consumption, the formation of the active radicals $\mathrm{OH}$ and $\mathrm{H}$ and production of the stable products $\left(\mathrm{H}_{2} \mathrm{O}, \mathrm{CO}\right.$ and $\left.\mathrm{CO}_{2}\right)$ are evident. $\mathrm{H}_{2} \mathrm{O}$ and $\mathrm{CO}$ appear in 


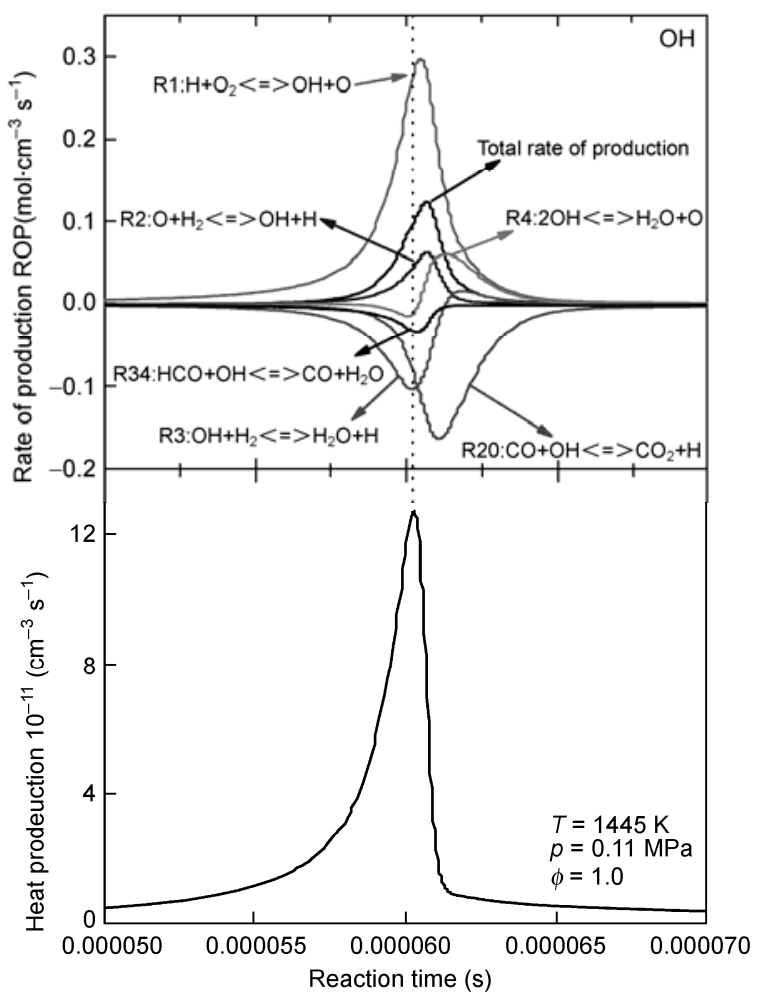

Figure 7 Rate of production for $\mathrm{OH}$ radical and instantaneous heat production of the surrogate on ignition at $1445 \mathrm{~K}, 0.11 \mathrm{MPa}$ and an equivalent ratio of 1.0 using Honnet et al.'s [5] mechanism.

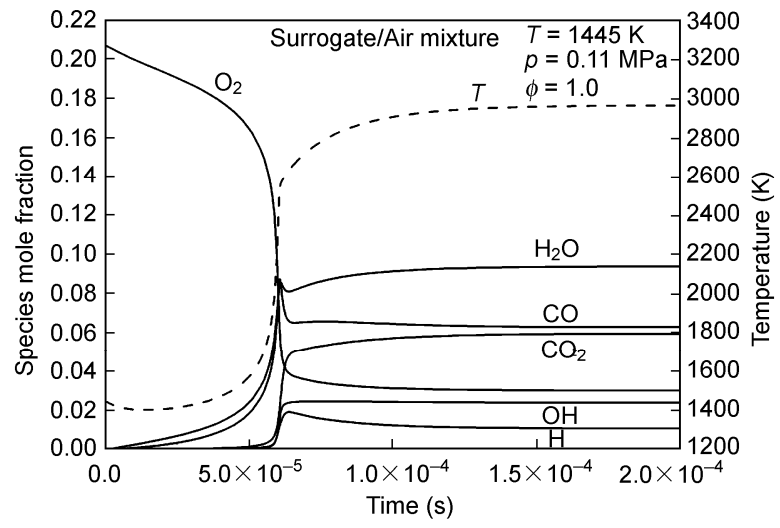

Figure 8 Flame structure analysis of surrogate on ignition at temperature of $1445 \mathrm{~K}$, pressure of $0.11 \mathrm{MPa}$ and equivalent ratio of 1.0 using Honnet et al. [5] mechanism.

the early ignition stage as the reaction temperature is increased with the consumption of $\mathrm{O}_{2}$. The $\mathrm{CO}$ radical concentration decreases after reaching its maximum value because of the consumption of $\mathrm{O}_{2}$ which leads to a late appearance of maximum $\mathrm{CO}_{2}$ to $\mathrm{CO}$ radical. Appearance of the $\mathrm{OH}$ radical corresponds to the beginning of significant ignition. $\mathrm{H}_{2} \mathrm{O}$ and $\mathrm{CO}$ concentrations increase slowly before the main ignition because of the decomposition and oxidation of small heavy hydrocarbons in kerosene. The stable products, $\mathrm{H}_{2} \mathrm{O}$ and $\mathrm{CO}$, form when pressure and temperature are elevated behind the incident and reflected shock waves. Simultaneous heat generation by these reactions changes the thermodynamic state of the uncombusted mixtures, and this is the main reason for a slight pressure increase before strong ignition as shown in Figure 2.

\section{Conclusions}

An experimental and numerical study on the combustion of stoichiometric kerosene/air mixtures was conducted at temperatures from $1445-1650 \mathrm{~K}$ at atmospheric pressure. The main conclusions are summarized as follows:

(1) Visualization analysis by ICCD indicates that the kerosene/air mixture flame is composed of isolated flame kernels and a continuous, uniform and irregular flame shape below $1515 \mathrm{~K}$. The mixtures are ignited at almost the same location to form a high luminous plane flame and propagate towards the driver section along the axes of the shock tube.

(2) Calculation of the thermodynamic state behind the reflected shock wave is reasonable using standard one-dimensional shock relations. Ignition delay times of kerosene/air mixtures decrease with an increase in temperature, and the global activation energy remains unchanged. This is consistent with the ignition characteristics of hydrocarbons at high temperature.

(3) A new surrogate, which consists of $10 \%$ toluene, $10 \%$ ethylbenzene and $80 \% \mathrm{n}$-decane, is used to simulate the ignition delay time of kerosene using Honnet et al.'s [5] mechanism. Calculations show good agreement with experimental data.

(4) A sensitivity analysis on the surrogate indicates that the reaction $\mathrm{H}+\mathrm{O}_{2}<=>\mathrm{OH}+\mathrm{O}$ has the highest sensitivity coefficient to the ignition delay times and the sensitivity increases with increase in temperature. Chain reactions are enhanced by the consumption of $\mathrm{CH}_{3}$ and suppressed by the $\mathrm{H}$-atom abstraction reactions of $\mathrm{n}$-decane. The rate of production analysis indicates that $\mathrm{H}+\mathrm{O}_{2}<=>\mathrm{OH}+\mathrm{O}$ and $\mathrm{O}+\mathrm{H}_{2}<=>\mathrm{OH}+\mathrm{H}$ are the main formation reactions of the $\mathrm{OH}$ radical. The instantaneous heat production recognizes $\mathrm{R} 3$ as the main heat generation reaction. The flame structure indicates that the initial pressure increases before ignition because of the formation of the stable products $\mathrm{H}_{2} \mathrm{O}$ and $\mathrm{CO}$ in the early ignition stage.

This work was supported by the National Natural Science Foundation of China (50876085 and 50821604).

1 Curran E T. Scramjet engines: The first forty years. J Propul Power, 2001, 17: 1138-1148

2 Char J M, Liou W J, Yeh J H, Chiu C L. Ignition and combustion study of JP-8 fuel in a supersonic flow field. Shock Waves, 1996, 6: 259-266

3 Vasu S S, Davidson D F, Hanson R K. Jet fuel ignition delay times: Shock tube experiments over wide conditions and surrogate model predictions. Combust Flame, 2008, 152: 125-143 
4 Ranzi E, Frassoldati A, Granata C, et al. Wide range kinetic modeling study of the pyrolysis, partial oxidation, and combustion of heavy n-alkanes. Ind Eng Chem Res, 2005, 44: 5170-5183

5 Honnet S, Seshadri K, Niemann U, et al. A surrogate fuel for kerosene. P Combust Inst, 2009, 32: 485-492

6 Liao Q, Xu S L. The ignition delay measurement of atomized kerosene air mixture in an aerosol shock tube. J Exp Fluid Mech, 2009, 23: $70-74$

7 Davidson D F, Haylett D R, Hanson R K. Development of an aerosol shock tube for kinetic studies of low vapor pressure fuels. Combust Flame, 2008, 155: 108-117

8 Wang G F, Ma C B, Wang B Y, et al. Direct observations of reaction zone structure in shock induced ignition of methane air mixure. Chinese Sci Bull, 2009, 54: 2247-2255

9 Horning D C, Davidson D F, Hanson R K. Study of the high temperature autoignition of $\mathrm{n}$-alkane/ $\mathrm{O}_{2} / \mathrm{Ar}$ mixtures. J Propul Power, 2002, 18: 363-371

10 Vasudevan V, Davidson D F, Hanson R K. Shock tube measurements of toluene ignition times and $\mathrm{OH}$ concentration time histories. $\mathrm{P}$ Combust Inst, 2005, 30: 1155-1163
11 Dagaut P, Cathonnet M. The ignition, oxidation, and combustion of kerosene: A review of experimental and kinetic modeling. Prog Energ Combust Sci, 2006, 32: 48-92

12 Patterson P M, Kyne A G, Pourkashanian M et al. Combustion of kerosene in counterflow diffusion flames. J Propul Power, 2001, 17: 453-460

13 Edwards T, Maurice L Q, Surrogate mixtures to represent complex aviation and rocket fuels. J Propul Power, 2001, 17: 461-466

14 Turanyi T. Applications of sensitivity analysis to combustion chemistry. Reliab Eng Syst Safety, 1997, 57: 41-48

15 Turanyi T, Tomlin A S, Pilling M J. On the error of the quasi steady state approximation. J Phys Chem, 1993, 97: 163-172

16 Dagaut P. On the kinetics of hydrocarbons oxidation from natural gas to kerosene and diesel fuel. Phys Chem Chem Phys, 2002, 4: 2079-2094

17 Shen H S, Vanderover J, Oehlschlaeger M A. A shock tube study of iso-octane ignition at elevated pressures: The influence of diluent gases. Combust Flame, 2008, 115: 739-755

18 Curran H J, Gaffuri P, Pitz W J. A comprehensive modeling study of iso-octane oxidation. Combust Flame, 2002, 129: 253-280

Open Access This article is distributed under the terms of the Creative Commons Attribution License which permits any use, distribution, and reproduction in any medium, provided the original author(s) and source are credited. 